\title{
Перспективы формирования качественного изображения в тепловизорах на базе отечественных фотоприемников КРТ
}

\author{
И.И. Кремис ${ }^{1)}$, Р.А. Гладков ${ }^{1)}$ \\ ${ }^{1}$ Филиал ИФП СО РАН «КТИПМ», Новосибирск, \\ 630090, Николаева, 8 \\ тел:+7 (383) 330-6559, факс:+7 (383) 316-5726, эл. почта: igor21738@ngs.ru
}

DOI 10.34077/RCSP2019-174

Трудности формирования качественного тепловизионного изображения с фотоприемников КРТ, прежде всего, связаны с их повышенной неоднородностью чувствительности, в сравнении с зарубежными фотоприемниками [1]. Данная неоднородность имманентно присутствует в изделиях КРТ и используемая, наиболее распространенная схема ее коррекции - по двум точкам, зачастую не позволяет осуществлять выравнивание изображения с приемлемой для потребителя точностью. Вследствие чего на изображении появляется «остаточная неоднородность» - в виде полос, вуали, дефектных строк и кластеров.

В этой связи, в Филиале ИФП СО РАН «КТИПМ» был разработан комплекс решений, позволяющих повысить точность коррекции тепловизионных изображений и тем самым расширить перспективы использования отечественных КРТ фотоприёмных устройств в изделиях ВВСТ.

Основная идея предложенных решений - использование систем сканирования сцены наблюдения для получения устойчивых решений коррекции неоднородности чувствительности.

Разработанный комплекс решений состоит из:

- систем микросканирования проекции изображения для перспективных тепловизионных каналов на базе матричных фотоприемных устройств [2];

- метода коррекции неоднородности в ТВК на базе МФПУ с использованием частотного разложения и микросканирования [3];

- метода коррекции неоднородности в ТВК на базе ЛФПУ с использованием частотного разложения и горизонтального сканирования сцены [4].

Комплекс предложенных решений обеспечивает фильтрацию остаточной неоднородности в реальном времени и позволяет существенно повысить качество тепловизионного изображения в ТВК на базе отечественных ФПУ $[1,3,4]$ при улучшении параметров эквивалентной шуму разности температур и минимально разрешаемой разности температур.

\section{Лuтература}

[1] И.И. Кремис. // Успехи прикладной физики. 2018. Т.6, вып.5.

[2] И.И. Кремис. // Успехи прикладной физики. 2017. Т.5, вып.2.

[3] И.И. Кремис, Д. А. Толмачев, Р. А. Гладков. // Прикладная физика. 2017, вып.1.

[4] И.И. Кремис, Д.А.Толмачев. // Прикладная физика. 2016, вып.6. 